\title{
A Novel Water Pretreatment Approach for Turbidity Removal Using Date Seeds and Pollen Sheath
}

\author{
Mukheled Al-Sameraiy \\ Environmental Research Center, University of Technology, Baghdad, Iraq \\ Email: mukheled@yahoo.com
}

Received December 13, 2011; revised January 18, 2012; accepted February 3, 2012

\begin{abstract}
Turbidity is a characteristic related to the concentration of suspended solids particles in water and has been adopted as an easy and reasonably accurate measure of overall water quality. The most widely applied water treatment processes, a combination of some or all of coagulation, flocculation, sedimentation and filtration to reduce or eliminate turbidity and improve water quality. In this research, proposed approach was adopted on the basis of applying two sequent treatments that used coagulation, flocculation and sedimentation processes under certain operating conditions of mixing speed, mixing time and settling time for each treatment. The environmentally friendly natural coagulants of date seeds (DS) or pollen sheath (PS) from local Iraqi palm was used in the first treatment and alum was used in the second treatment at their predetermined optimum doses to treat low $(75 \pm 10 \mathrm{NTU})$, medium $(150 \pm 10 \mathrm{NTU})$ and high $(300 \pm 10 \mathrm{NTU})$ bentonite synthetic turbid water. Experimental results clearly show that the proposed approach was superior in performance in terms of residual turbidity compared with conventional approach using both of (DS) and (PS) natural coagulants in which it achieved a significant reduction in turbidity to less of 5 NTU that meeting WHO drinking water guidelines for all tested synthetic turbid water. Moreover, in some cases, it produced excellent water quality having residual turbidity less of 0.1 NTU. In addition to decrease the settling time to 30 minutes and minimize risks of alum dose required to $60 \%$. These viable advantages are significant to current practices in advanced water treatment technologies such as reverse osmosis in cost, energy, effectiveness, safety and maintenance. So, it is recommended to consider proposed approach in this research work to be a novel pretreatment approach in advanced water treatment.
\end{abstract}

Keywords: Coagulation; Flocculation; Date Seeds; Pollen Sheath; Turbidity Removal; Bentonite

\section{Introduction}

Turbidity can be used to measure the performance of individual treatment processes as well as the performance of an overall water treatment system. Common water treatment processes intended to remove suspended solids and reduce turbidity include: coagulation, flocculation, sedimentation and filtration [1].

Coagulation is the process of conditioning suspended solids particles to promote their agglomeration and produce larger particles that can be more readily removed in subsequent treatment processes. The process of coagulation is complex and may involve several different mechanisms to achieve "destabilization", which allows particle agglomeration and enhances subsequent removal [2]. Flocculation is the process of bringing the destabilized particles into contact with one another to form larger "floc" particles. These larger particles are more readily removed from the water in subsequent processes [1].

A coagulant is one of the key components for removing turbidity in a water treatment process [3,4]. Many coagulants are widely used in conventional water treat- ment processes. These materials can be classified into inorganic and organic coagulants [5]. Inorganic coagulants such as aluminum and iron salts are most widely used in the coagulation process [6]. Aluminum is regarded as an important poisoning factor in dialysis encephalopathy. Also, there is strong evidence linking aluminum-based coagulants to the development of neurodegenerative illnesses as senil dementia [7] and with Alzheimer's disease in human beings [8].

Organic coagulants (polymers) are often termed polyelectrolytes are broadly classified into synthetic and natural origin. Synthetic polyelectrolytes are cuestionated due to the toxicity and carcinogenetic potential of the monomers used for their synthesis [9]. For these reasons, it is desirable a progressive replacement of these chemical coagulants with alternative coagulants preferably from natural and renewable sources. Natural coagulants (biopolymers) would be of great interest since they are natural low-cost products, characterized by their environmentally friendly behavior, and presumed to be safe for human health. There has been considerable interest in the 
development of usage of natural coagulants [10] which can be produced or extracted from microorganisms, animal or plant tissues. These coagulants produce readily biodegradable and less voluminous sludge that amounts only $20 \%-30 \%$ that of alum treated counterpart [11]. Different environmentally friendly coagulants are proposed as an important alternative for water treatment from plant origin such as nirmali seed and maize [12], mesquite bean and cactus latifaria [13], cassia angustifolia seed [14], different leguminose species [15], acorn [16], coccinia indica fruit mucilage [17]. Nowadays, the material which has recently received the greatest attention of many researchers such as $[18,19]$ is moringa oleifera. It has a very good coagulating activity in the clarification of turbid water as primary coagulant and as coagulant aid with alum.

The objective of this research is to develop a new approach using coagulation-flocculation-sedimentation processes at certain operating conditions depending on an investigated optimum doses of natural coagulants of date seeds (DS), pollen sheath (PS), and inorganic coagulant (alum) for treating low, medium and high bentonite synthetic turbid water to obtain better quality of treated water meeting WHO turbidity standard of drinking water. The performance of proposed approach would be assessed and compared with conventional approach on the basis of minimizing risks of alum dose required, reducing the settling time of suspended solids and decreasing residual turbidity.

\section{Materials and Methods}

\subsection{Preparation of Synthetic Turbid Water}

Bentonite was collected from a local site (Al-Anbar Governate, Western desert). Synthetic turbid water was prepared by adding different weights of bentonite in $(\mathrm{mg})$ into $1 \mathrm{~L}$ of distilled water. Bentonite suspension was resuspended by rapid mechanical agitation $(300 \mathrm{rpm})$ for 5 minutes in a jar test apparatus (ECE CLM6, Compact Laboratory Mixer) followed by 30 minutes of slow mixing $(40 \mathrm{rpm})$ to obtain a uniform dispersion of bentonite particles. After that it was left to settle for 10 minutes. Turbidity of the supernatant liquors was measured by (Turbi Direct, Lovibond, Germany) and expressed in nephelometric turbidity unit (NTU). The procedure for measurement was conformed to that described in Standard Methods for the Examination of Water and Wastewater [20]. Each experiment was carried out in duplicate and the mean values of obtained turbidities were reported and plotted against the concentration of bentonite in $(\mathrm{mg} / \mathrm{L})$ as shown in Figure 1. The linear model was fit well the obtained experimental data with correlation coefficient, $\left(R^{2}\right)$ equal to 0.9959 . The linear model can be represented as:

$$
T=628.48 C-0.3183
$$

where $T$ is the prepared turbidity of control synthetic water in (NTU), $C$ is the bentonite clay concentration in $(\mathrm{mg} / \mathrm{L})$. This model was used to prepare three selected

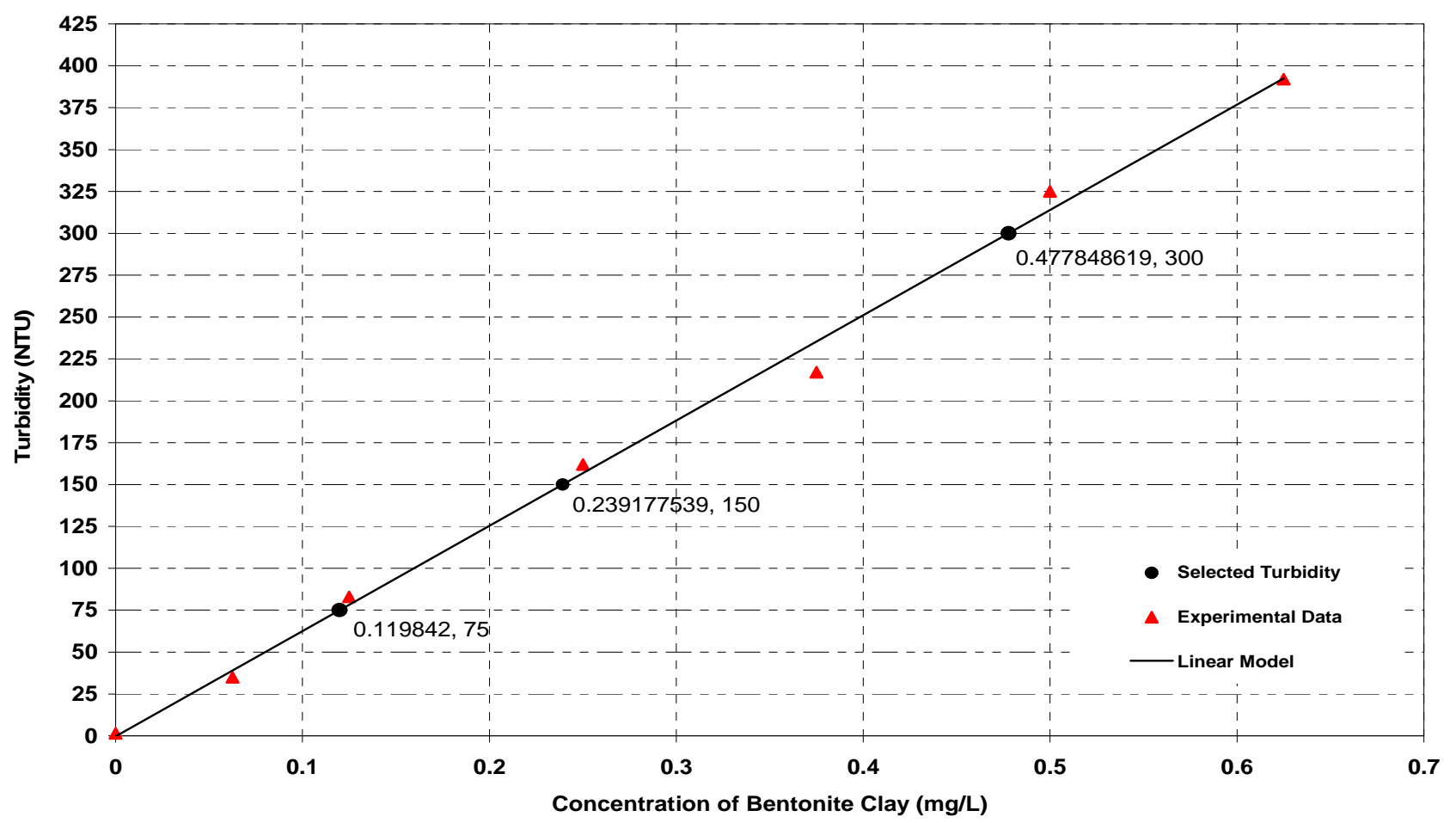

Figure 1. Synthetic turbid water as a function of bentonite clay concentration. 
levels of synthetic turbid water, namely, low $(75 \pm 10$ NTU), medium (150 $\pm 10 \mathrm{NTU})$ and high $(300 \pm 10 \mathrm{NTU})$ turbidities.

\subsection{Preparation of Alum Solution}

Alum $(A)$ solution was prepared by dissolving $1 \mathrm{~g}$ of alum $\left(\mathrm{Al}_{2}\left(\mathrm{SO}_{4}\right)_{3}\right)$ in distilled water $(\mathrm{pH}=7 \pm 0.1)$ and the solution volume was increased to $1 \mathrm{~L}$. Each $1 \mathrm{~mL}$ of prepared stock solution was equal to $10 \mathrm{mg} / \mathrm{L}$ when added to $1 \mathrm{~L}$ of synthetic turbid water to be tested [20].

\subsection{Preparation of Natural Coagulants Solutions}

Date seeds (DS) and pollen sheath (PS) of the local Iraqi palm were collected and used in this research. Each of them was washed in tap water and dried in an oven at $40^{\circ} \mathrm{C}$ for one day until dryness. They were powdered in a domestic grinder and sieved through a $300 \mu \mathrm{m}$ sieve. Each of (DS) and (PS) was accurately weighted (0.9 g) into a glass beaker and then added $0.1 \mathrm{~g}$ of $\mathrm{NaOH}$. After that, a certain volume of distilled water was added to the blend and stirred for 5 minutes at $300 \mathrm{rpm}$ using magnetic stirrer (Model L-81, Rlabinco). The volume of obtained suspension was increased to $1 \mathrm{~L}$ and then gravity filtered through a $1 \mu \mathrm{m}$ Whitman filter paper to separate residual particles from the prepared solution. The filtrate of (DS) and (PS) is referred to as natural coagulants in this work.

\subsection{Experimental Procedure}

A standard jar test apparatus equipped with six paddles rotating in a set of six beakers was used to simulate coagulation, flocculation and sedimentation processes. The selected level of bentonite synthetic turbid water $(1 \mathrm{~L})$ at room temperature $\left(25^{\circ} \mathrm{C}\right)$ was filled into the beakers and various doses in the range $(10-100 \mathrm{mg} / \mathrm{L})$ of natural coagulants (DS, PS) and the inorganic coagulant (alum, A) were separately added into the beakers and mixed rapidly (300 rpm) for 1 minute. The mixing speed was then reduced to $40 \mathrm{rpm}$ for 20 minutes. Then the stirrer was turned off and the suspensions were allowed to settle for different periods of time ranging from 30 to $120 \mathrm{~min}$ utes under quiescent conditions. After each period of settling time, supernatant samples of each beaker in the jar test were withdrawn from the located $10 \mathrm{~cm}$ below the water level and residual turbidity was measured (Ts). Control experiments for coagulation tests $\left(T_{B}\right)$ were performed in the absence of each coagulant of (DS), (PS) and $(A)$ to natural decantation of the suspension under each set of experimental conditions. The efficiency of turbidity removal, $R(\%)$ was calculated using the formula given:

$$
R(\%)=\left(T_{B}-T_{S}\right) \times 100 / T_{B}
$$

\section{Results and Discussions}

\subsection{Investigation of the Optimum Coagulants Doses}

Dosage is one of the most important parameters that has been considered to determine the optimum conditions for the coagulation and flocculation. Basically, insufficient dosage or overloading would result in the poor performance in flocculation. Therefore, it was crucial to determine the optimum dosage in order to minimize the dosing cost and obtain the optimum performance in treatment. In conventional water treatment practice, finding the optimum dose for each coagulant is a problem that must be solved and determined by empirical experiments $[5,21]$. So, a set of experiments were carried out using jar test apparatus to investigate the effect of equal investigated dosages of each coagulant of (DS), pollen sheath (PS) and alum (A) in the range of $10-100 \mathrm{mg} / \mathrm{L}$ on the synthetic turbid water prepared at low, medium and high turbidities in terms of turbidity removal efficiency $(R \%)$ under various settling times from 30 to 120 minutes. Figures 2-10 clearly show that for all range of settling time, the coagulants of (DS, PS and $A$ ) are able to achieve good removal efficiencies for all levels of synthetic turbid water that were calculated by using Equation (2). On the other hand, the best results of the percentage removal of turbidity were found at the settling time of 120 minutes. It was observed that there was an insignificant difference in the turbidity removal efficiency when the settling time was increased beyond 120 minutes. Thus, the settling time (120 minutes) will be used as a basis for comparing the efficiency of coagulants.

The maximum values of turbidity removal at low synthetic water were reported as $94 \%, 91 \%$ and $97 \%$ for DS, PS and $A$ coagulants respectively corresponding to the doses of 30,20 and $10 \mathrm{mg} / \mathrm{L}$ respectively as shown in Figures 2-4. These doses are to be the optimum doses for coagulation process.

In medium synthetic water, Figures $\mathbf{5}$ and $\mathbf{6}$ show the highest efficiency of turbidity removal of natural coagulants (DS) and (PS) was $90 \%$ and $92 \%$ corresponding to the optimum doses of 60 and $50 \mathrm{mg} / \mathrm{L}$ respectively. While in Figure 7, the highest turbidity removal of $97 \%$ was achieved at the optimum alum dose of $20 \mathrm{mg} / \mathrm{L}$.

Similar results were obtained with high synthetic turbid water as shown in Figures 8-10. The highest turbidity removal for coagulants of DS, PS and A were to be $83 \%, 93 \%$ and $99 \%$ respectively corresponding to the optimum doses of 80,90 and $60 \mathrm{mg} / \mathrm{L}$ respectively.

Several researches which reported that initially with an increase in the dose of coagulant, the percentage removal of turbidities increases, but after a certain dose, a decreasing trend in turbidity removal percentage with the increase of coagulant dose [22-24]. This behavior could 


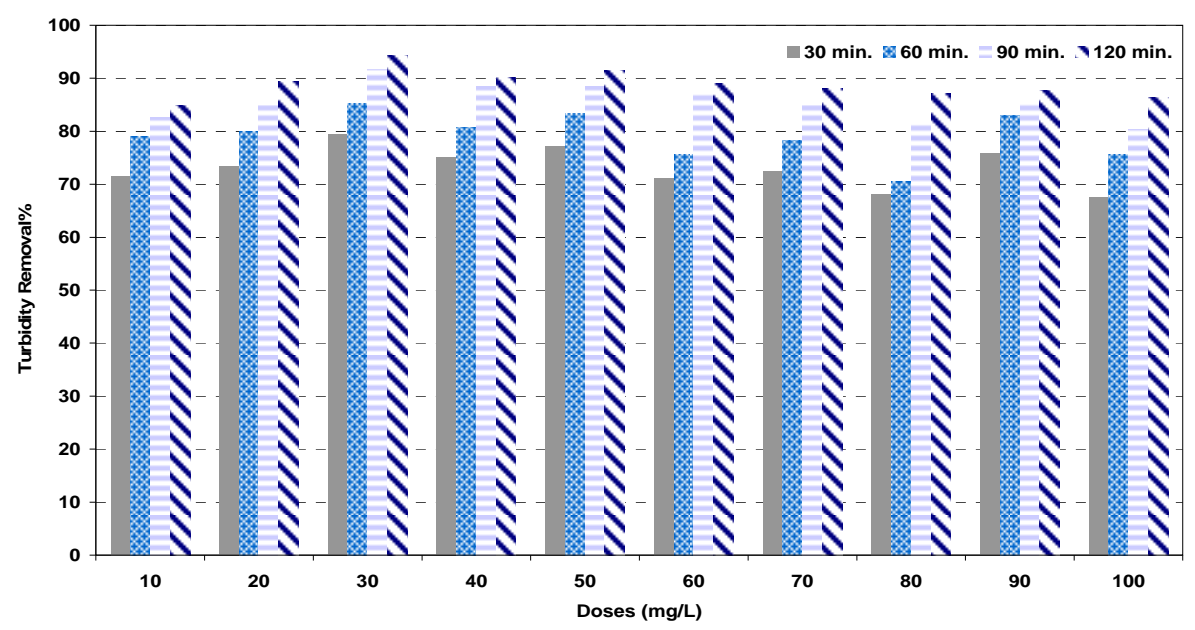

Figure 2. Effect of date seeds (DS) coagulant doses under various settling times on turbidity removal percent at low synthetic turbid water.

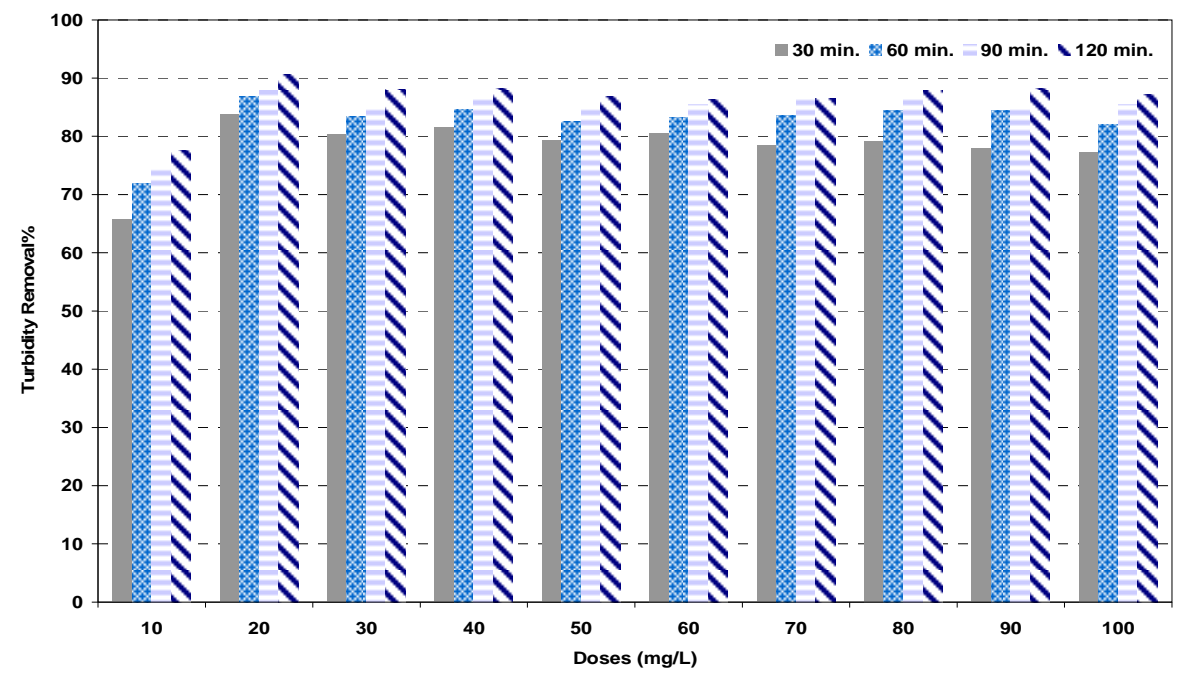

Figure 3. Effect of pollen sheath (PS) coagulant doses under various settling times on turbidity removal percent at low synthetic turbid water.

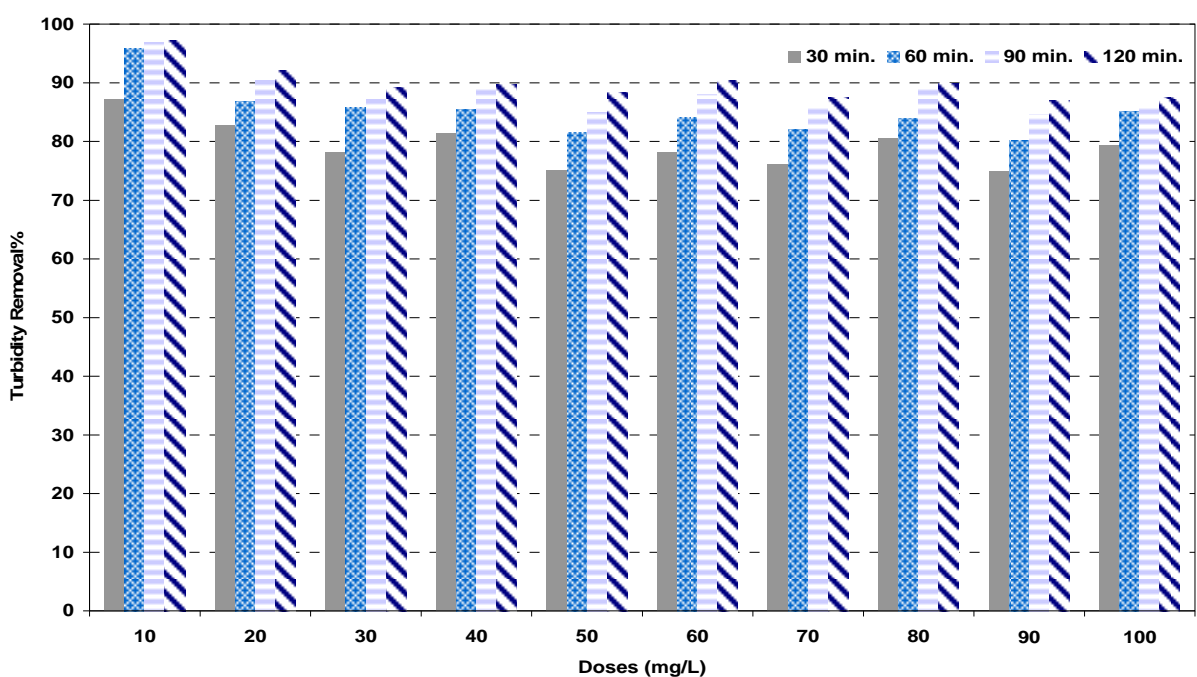

Figure 4. Effect of alum $(A)$ coagulant doses under various settling times on turbidity removal percent at low synthetic turbid water. 


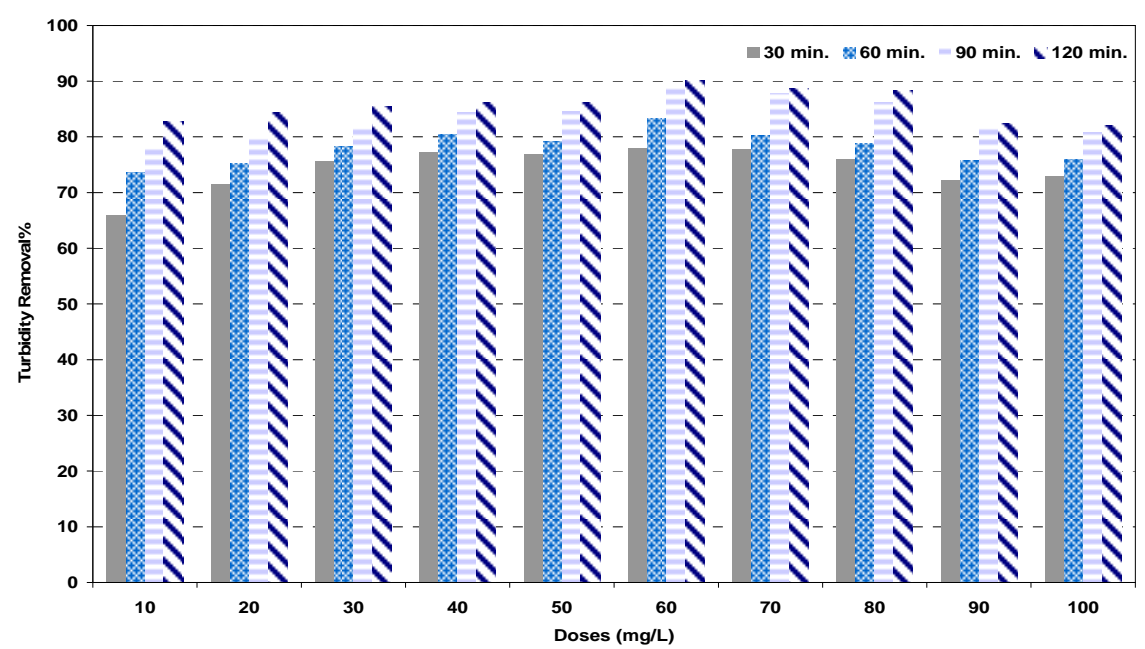

Figure 5. Effect of date seeds (DS) coagulant doses under various settling times on turbidity removal percent at medium synthetic turbid water.

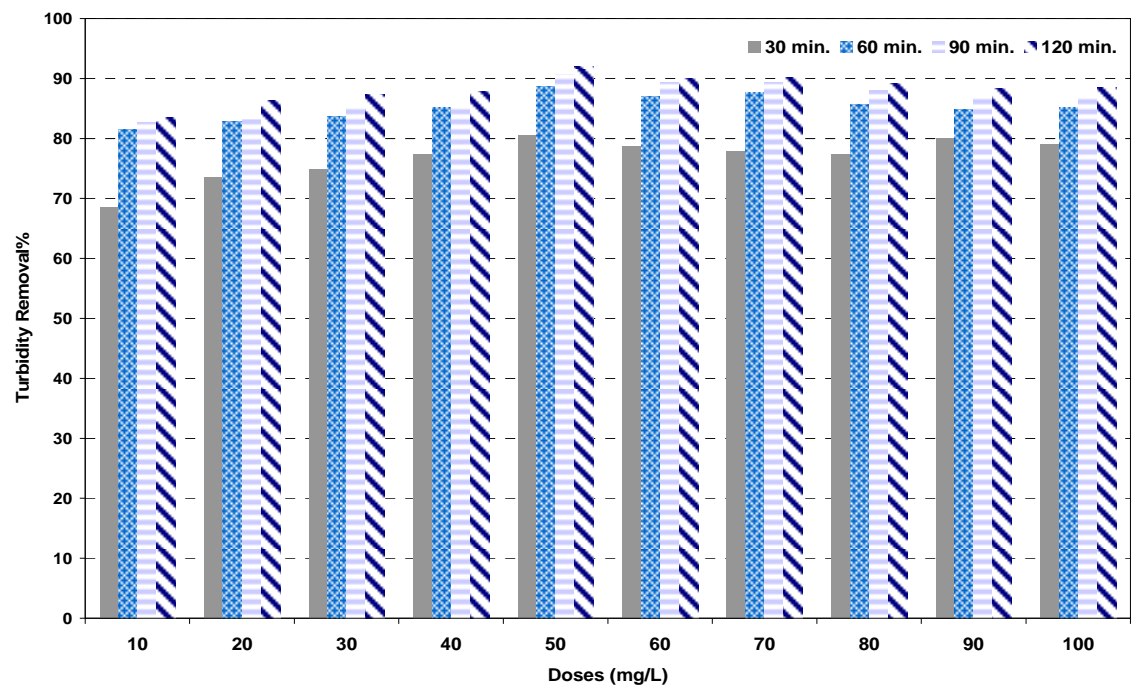

Figure 6. Effect of pollen sheath (PS) coagulant doses under various settling times on turbidity removal percent at medium synthetic turbid water.

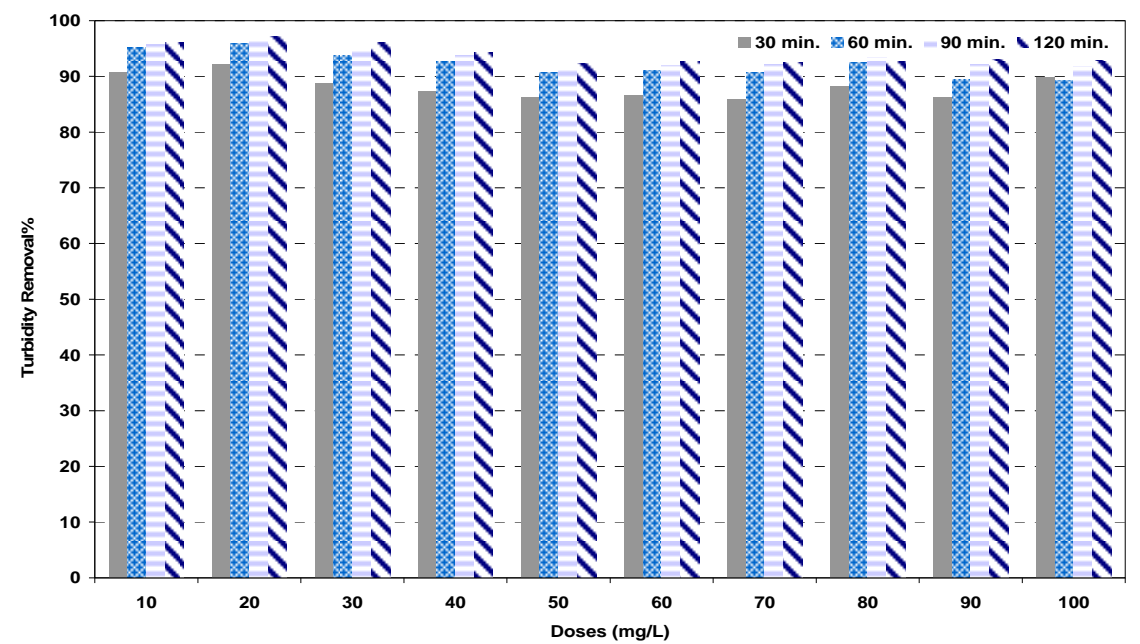

Figure 7. Effect of alum (A) coagulant under various settling times on turbidity removal percent at medium synthetic turbid water. 


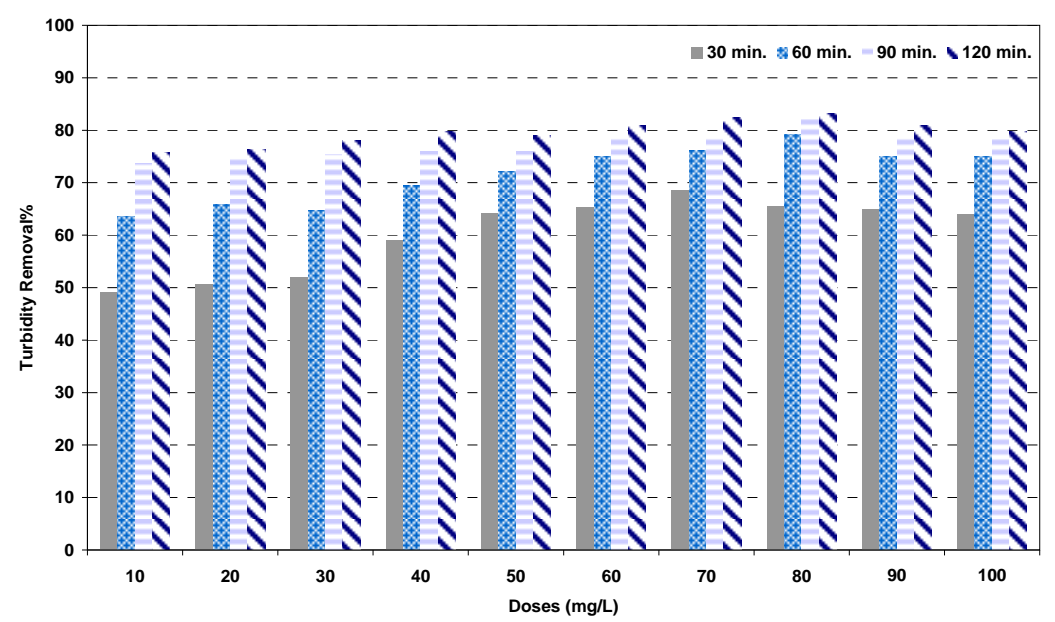

Figure 8. Effect of date seeds (DS) coagulant doses under various settling times on turbidity removal percent at high synthetic turbid water.

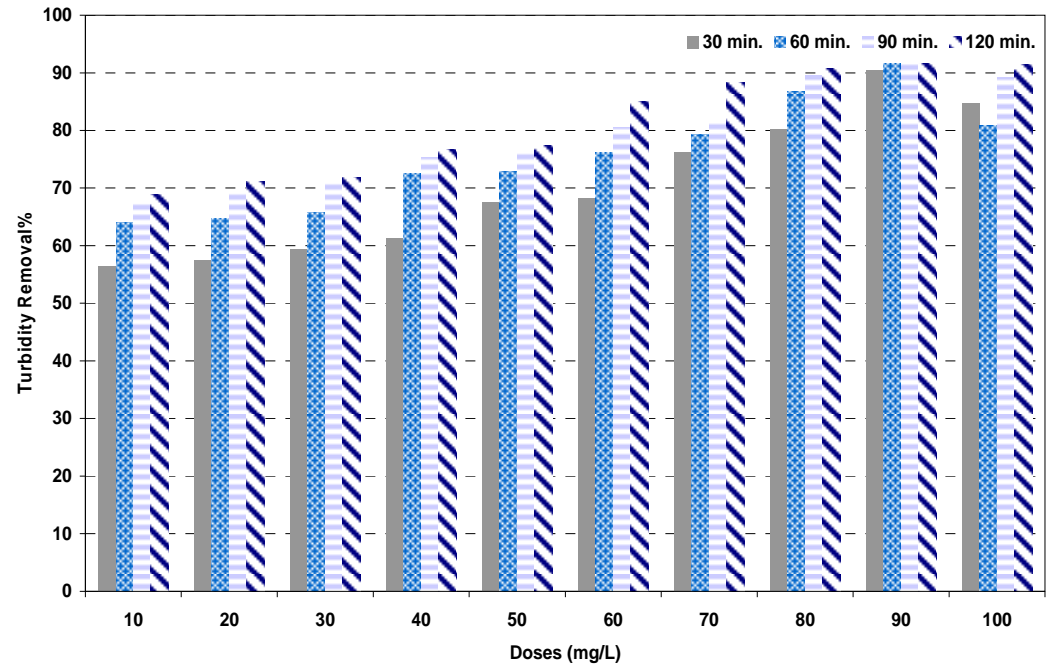

Figure 9. Effect of pollen sheath (PS) coagulant doses under various settling times on turbidity removal percent at high synthetic turbid water.

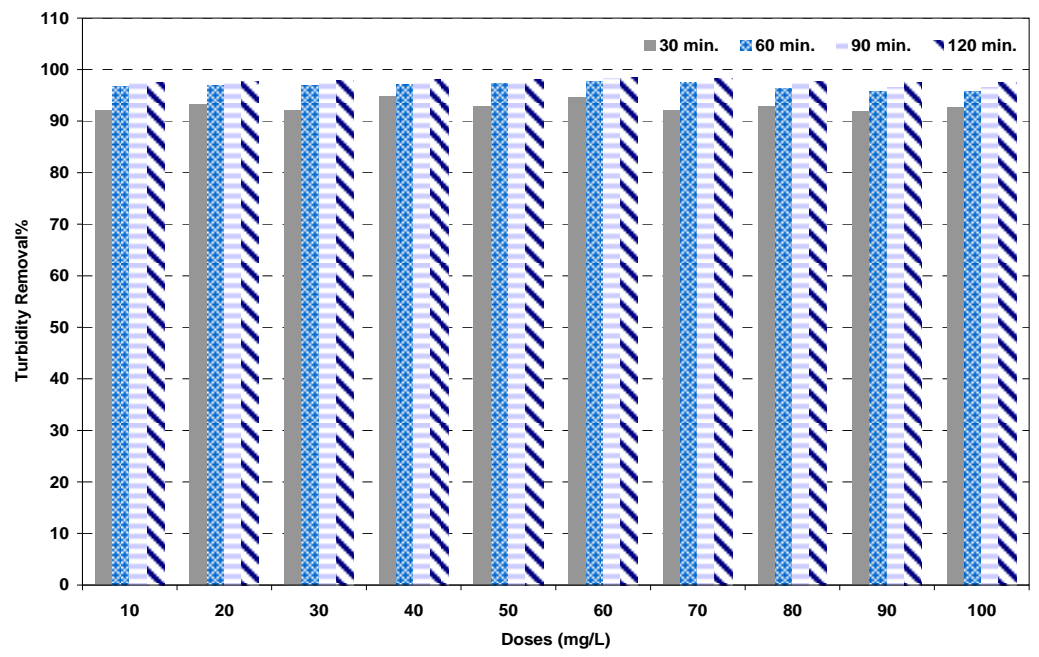

Figure 10. Effect of alum $(A)$ coagulant doses under various settling times on turbidity removal percent at high synthetic turbid water. 
be explained by the fact that the optimal dose of coagulant in suspension causes larger amount of solid to aggregate and settle. However an overoptimal amount coagulant would cause the aggregated particles to re-disperse in the suspension and would also disturb particle settling. The experimental results found in this work are in agreement with the literature where above the optimum doses for each coagulant found at three levels of synthetic turbid water, the suspension showed a tendency to restabilize and further increase in coagulant doses adversely affected turbidity removal [25].

It is obvious from the results are presented in Figures 2-10 that the coagulation activities in terms of turbidity removal efficiency $(R \%)$ of the investigated coagulants at their optimum doses showed similarly effective results and possessed positive coagulation abilities to treat various synthetic turbid water but they were not equal. These results of each investigated coagulant were shown in Figure 11; the percentage of turbidity removal of (DS) natural coagulant is higher than that of (PS) at low turbidity. While for medium and high initial turbidities, it was lower. On the other hand, alum coagulant expressed the highest coagulation activity for all tested levels of synthetic turbid water. So, it is of importance to mention that the coagulation activity $(R \%)$ of each coagulant has significantly been affected by the type of coagulant.

Also, Figure 11 showed that the coagulation activity $(R \%)$ of each coagulant used was found to be dependent on initial turbidity level of synthetic water. For example, at low turbidity, $R \%$ for DS natural coagulant was $94 \%$. While it was $90 \%$ and $83 \%$ for medium and high turbidities respectively. In other words, the turbidity removal efficiency is influenced by the initial turbidity of synthetic water. These results are constituent with those obtained by several researches [17,26-28]. So, coagulant dose is very important factor for coagulation efficiency that highly depends on optimum relationship between coagulant doses and bivalent cations in water [29].

\subsection{Residual Turbidity as Evaluating Parameter of Coagulants Performance}

The effect of settling rate of bentonite suspensions of control samples in the absence of each coagulant under various settling times in the range of 30 to 120 minutes on low, medium and high synthetic turbid water is shown in Figures 12-14. The exponential models were fit well the obtained experimental data of control samples with correlation coefficient, $\left(R^{2}\right)$ greater than $(0.95)$. The exponential model can be written as:

$$
R T=a e^{-b t}
$$

where $R T$ is the residual turbidity of control samples of synthetic turbid water in (NTU), $a$ and $b$ are correlating parameters measured in (NTU) and (1/min.) respectively, $t$ is the settling time (min.). The described model in Equation (3) has a physical meaning in which as the settling time approaches zero, the value of residual turbidity will represent approximately the initial turbidity of control

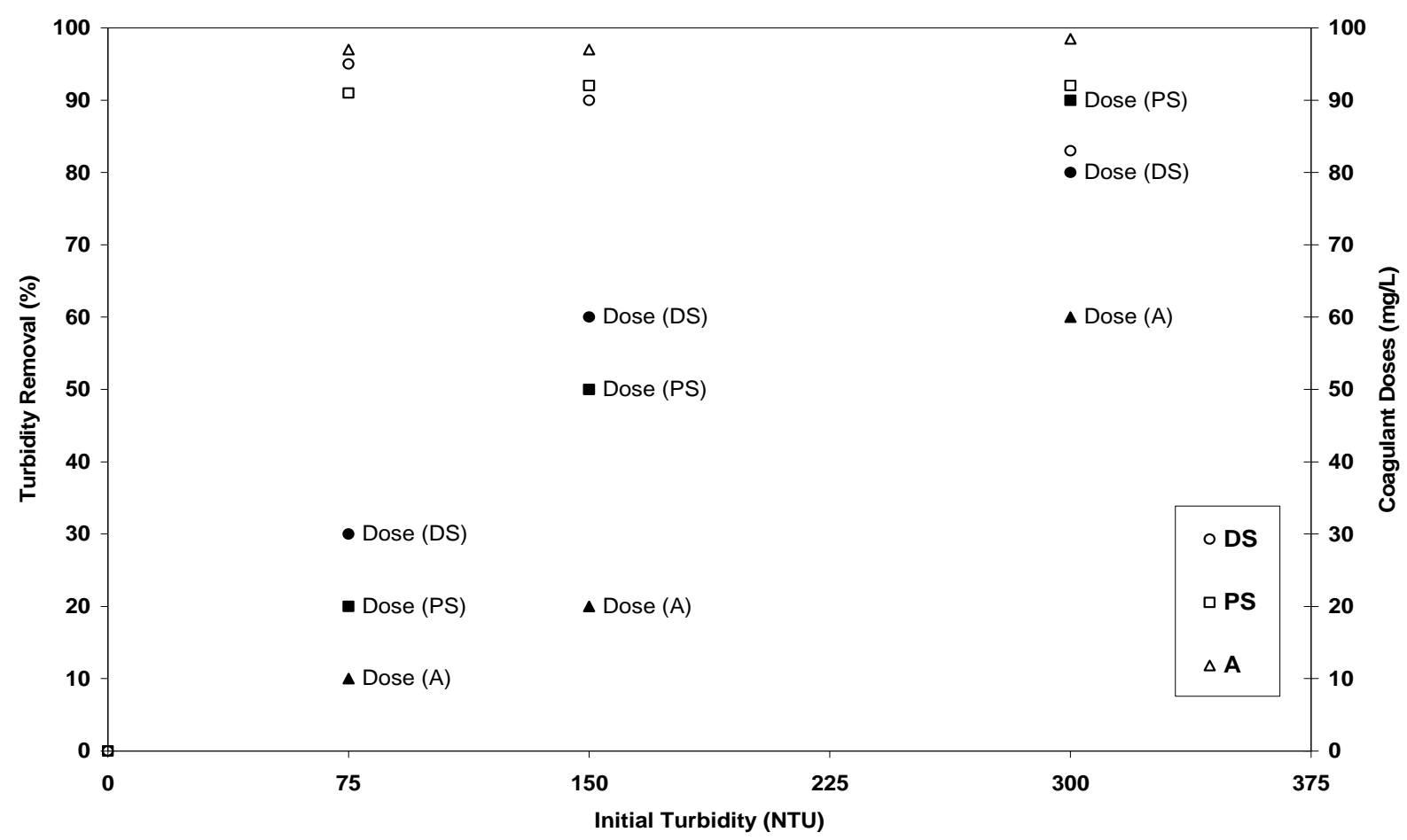

Figure 11. Effect of initial turbidity of synthetic water on the turbidity removal percent and coagulant doses of DS, PS and $A$. 


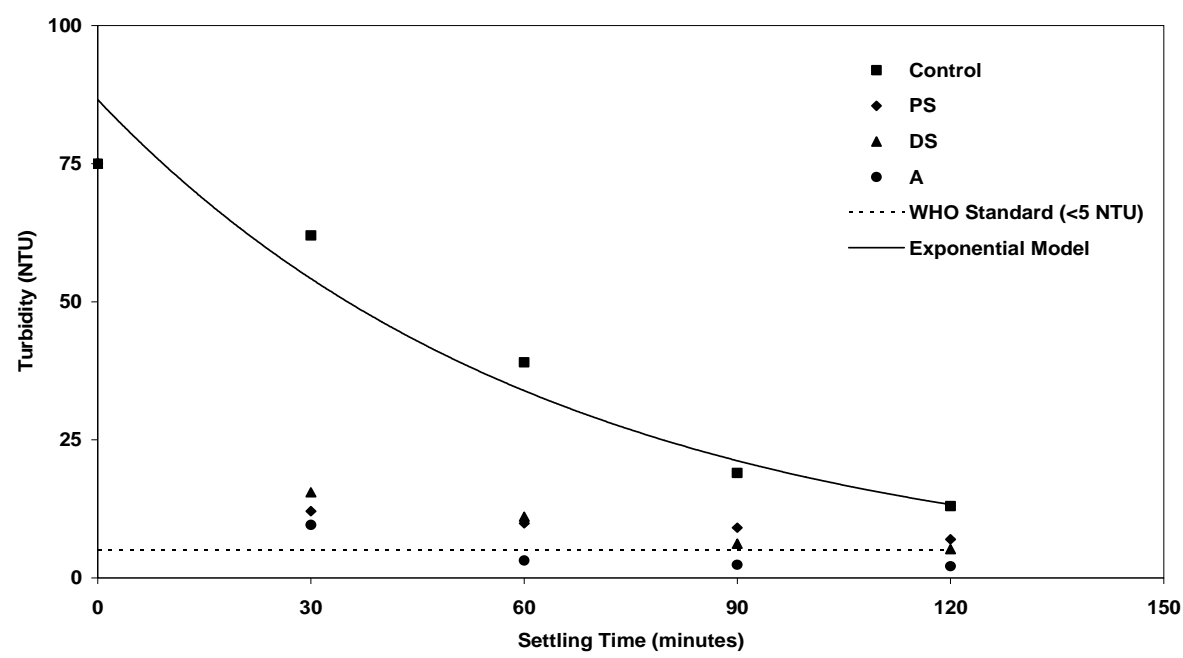

Figure 12. Evaluation of efficiency of PS, DS and $A$ coagulants compared with control samples at low synthetic turbid water.

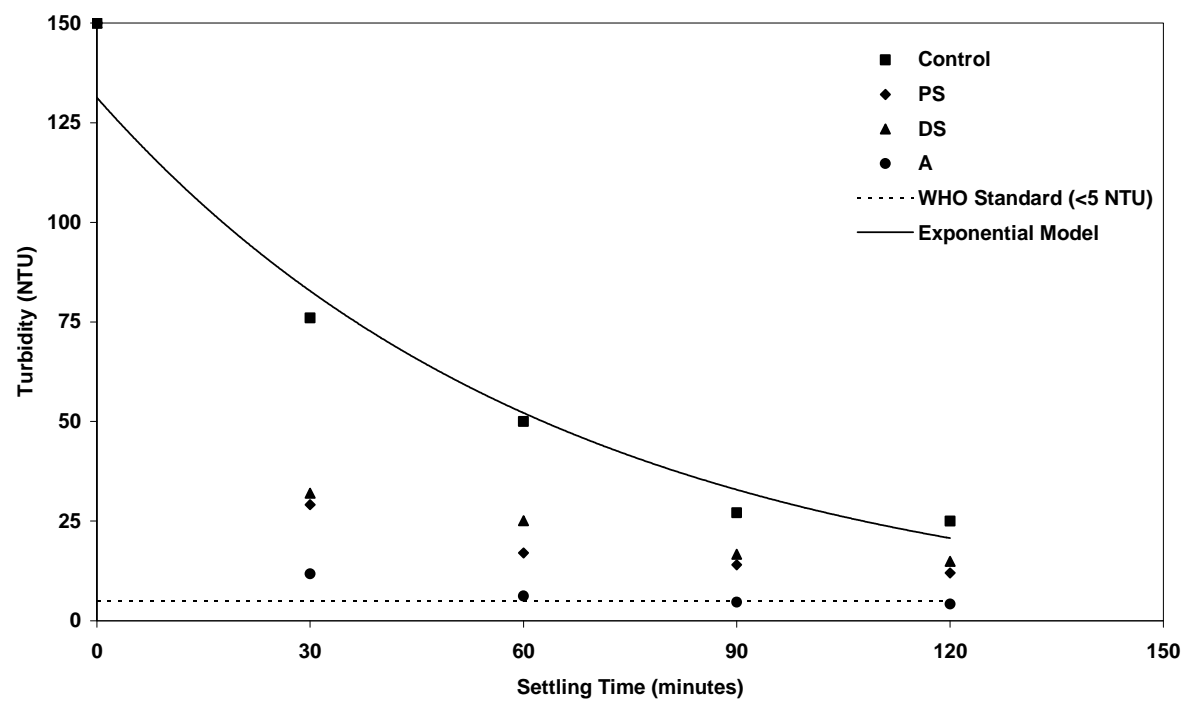

Figure 13. Evaluation of efficiency of PS, DS and $A$ coagulants compared with control samples at medium synthetic turbid water.

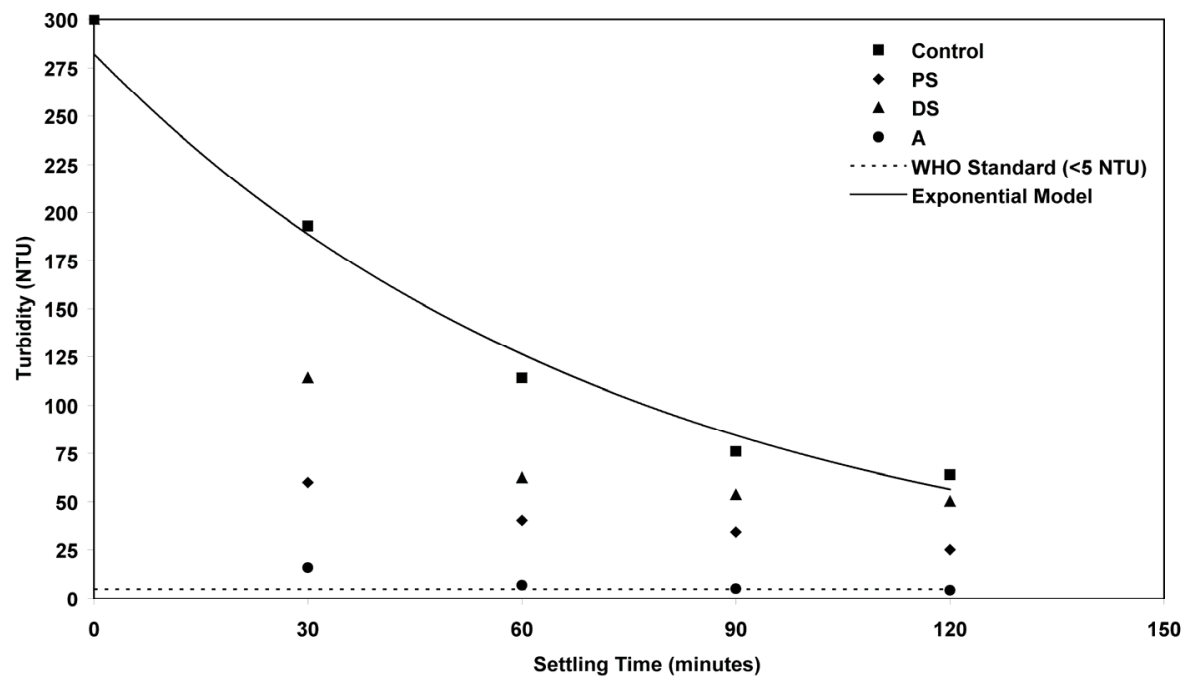

Figure 14. Evaluation of efficiency of PS, DS and A coagulants compared with control samples at high synthetic turbid water. 
samples. While the settling time goes to long period of time, the residual turbidity of control samples will reach to minimum value under quiescent condition. This model could be used for prediction of the final turbidity of synthetic water as a function of settling time. Table 1 shows the correlating parameters of exponential model of residual turbidity of control synthetic water at low, medium and high turbidities.

It is obvious to see from Figures 12-14 that the residual turbidities of low, medium and high of control bentonite synthetic water as a function of settling rate in the range of 30 to 120 minutes without addition of any coagulant were greater than the value of standard drinking water. World Health Organization (WHO) recommends that if turbidity is more than $5 \mathrm{NTU}$, some treatment is necessary to remove the turbidity before the water can be effectively disinfected [30]. So, several experiments were performed to increase the control settling rate of three levels of synthetic turbid water using different doses of investigated coagulants. The best results obtained at the optimum doses of each coagulant as shown in Figures 2-10 were selected on the basis of highest removal efficiencies. On the other hand, these highest removal efficiencies correspond to minimum residual turbidities. In Figures 12-14, minimum residual turbidities were basically used for evaluating the efficiency of each coagulant compared with the control samples. It can be clearly seen from these figures that the best results were noticed at settling time (120 minutes).

In Figure 12, the residual turbidities of DS (5.2 NTU) and PS (7 NTU) natural coagulants could not reach to the standard value (less than 5 NTU) in drinking water. While after addition of alum, the settling rate of control sample was increased very fast and resulted in substantial improvement in residual turbidity such as $(3.15,2.36$, $2.10 \mathrm{NTU})$ for three settling times (60, 90, 120 minutes) respectively. These values of residual turbidities are acceptable according to WHO guidelines for safe drinking water. This indicates that alum coagulant at the optimum dose has a very good coagulating activity in the turbidity removal for low synthetic turbid water.

In Figure 13, the residual turbidities of natural coagulants of DS and PS were found to be 14.9 and 12 NTU respectively higher than that of standard value in drinking water. While for alum coagulant, they were 4.66 and 4.18 NTU at two settling times of 90 and 120 minutes respectively. These values of residual turbidities are within the WHO drinking water guidelines value for turbidity.

In Figure 14, the residual turbidities of DS (50.2 NTU) and PS (25 NTU) were higher than that of standard value in drinking water. While for alum coagulant, at settling time 120 minutes, it was 4.41 NTU that meeting WHO drinking water guidelines for safe drinking water.
Table 1. Regressed parameter values of exponential model (Equation (3)) for various control synthetic turbid water.

\begin{tabular}{cccc}
\hline Control turbidity level & $\boldsymbol{a}$ & $\boldsymbol{b}$ & $\boldsymbol{R}^{2}$ \\
\hline Low & 86.58 & -0.0156 & 0.9687 \\
Medium & 131.28 & -0.0154 & 0.9554 \\
High & 282.25 & -0.0134 & 0.9751 \\
\hline
\end{tabular}

\subsection{Comparison of Applied Approaches Performance of Turbidity Removal}

\subsubsection{Conventional Approach}

Based on the obtained results shown in Figures 2-14, it can be clearly observed that both natural coagulants of (DS) and (PS) achieved a significant improvement in the percentage of turbidity removal of synthetic turbid water under various levels of prepared turbidities. On the other hand, in terms of residual turbidities, both of them could not achieve the acceptable limit of safe drinking water. While for alum coagulant, residual turbidities were less of 5 NTU for low, medium and high synthetic turbid water that meeting WHO drinking water guidelines. Therefore, alum could be used as a primary coagulant. While natural coagulants of DS and PS could be used as coagulant aids in the conventional approach. Primary coagulants are used to cause the particles to become destabilized and begin to clump together. The purpose of coagulant aids may be to condition the water for the primary coagulant being used [31], to achieve optimum conditions for coagulation and flocculation, to obtain faster floc formation, produce denser and stronger flocs, decrease the coagulant dosage, broaden the effective $\mathrm{pH}$ band, and improve the removal of turbidly [32].

Poor performance was obtained by $[33,34]$ when chitosan coagulant aid and alum were added simultaneously. Good results obtained when chitosan coagulant aid was added one minute after addition of alum. The same result was obtained by [33] who used natural polyelectrolyte as coagulant aid. So, in this research work, the delay time between the addition of natural coagulant aids and primary coagulant in conventional approach was considered to achieve a good performance. Each of natural coagulant of (DS) and (PS) at their predetermined optimum doses used as a coagulant aids was added to control bentonite turbid water $(1 \mathrm{~L})$ prepared at different selected levels of turbidity and mixed rapidly $(300 \mathrm{rpm})$ for 1 minute. After that, alum used as a primary coagulant was added to the jar beakers under various investigated doses in the range of $2-10,4-20$ and $12-60 \mathrm{mg} / \mathrm{L}$ for low, medium and high synthetic turbid water respectively and mixed rapidly (300 rpm) for 1 minute. The mixing speed was then reduced to $40 \mathrm{rpm}$ for 20 minutes. The stirrer was turned off and the suspensions were allowed to settle for different periods of time $(30-120)$ minutes under quiescent 
conditions. After each period of settling time, supernatant samples of each beaker were withdrawn and residual turbidities were directly measured.

\subsubsection{Proposed Approach}

Coagulation by itself does not achieve turbidity reduction; in fact turbidity may increase the coagulation process due to the additional insoluble compounds generated through chemical addition. The subsequent processes of flocculation, sedimentation and filtration are used in conjunction with coagulation to achieve turbidity reduction. In coagulation process, rapid mixing is utilized to distribute the coagulant throughout the tested water. In flocculation process, slow mixing is a key aspect to achieve optimum performance. While mixing time is a key performance parameter. Adequate time must be provided to allow generation of particles sufficiently large to allow their efficient removal in sedimentation process [32].

The proposed approach was adopted on the basis of treating synthetic turbid water consisting of a combination of two similar serial treatments that used coagulation-flocculation-sedimentation processes under certain operating conditions of mixing speed, mixing time and settling time for each of them. Another adoption of this approach was to apply the natural coagulant of DS or PS in the first treatment as a primary coagulant and alum coagulant in the second treatment as a primary coagulant.

Various levels of control bentonite turbid water (1 L) were filled into the jar beakers. Selected natural coagulant of (DS) or (PS) at its predetermined optimum dose of each turbidity level of tested synthetic water was added into the beakers and mixed vigorously (300 rpm) for 1 minute followed by 10 minutes of gentle mixing speed $(40 \mathrm{rpm})$. The stirrer was turned off and the suspensions were allowed to settle for 15 minutes under quiescent conditions. After that, the supernatant samples of each beaker were withdrawn and transferred into other empty beakers. Alum was added under various investigated doses in the range of $2-10,4-20$ and $12-60 \mathrm{mg} / \mathrm{L}$ for low, medium and high synthetic turbid water respectively to the beakers that contained supernatant samples and mixed rapidly (300 rpm) for 1 minute followed by 10 minutes of slow mixing speed $(40 \mathrm{rpm})$. Then the stirrer was turned off and the suspensions were allowed to settle for 15 minutes under quiescent conditions. Treated samples of each beaker were withdrawn and residual turbidity was directly measured. This measuring value corresponds to setting time of 30 minutes. Other measurements of residual turbidities were done after the settling time ranging from 60 to 120 minutes. On the basis of the comparison of performance between conventional and proposed approaches, the operating parameters which are selected to use in both treatments of proposed approach was equivalent to that used in conventional approach. In other words, the mixing speed of coagulation and flocculation process for both approaches was equal. While the mixing time of flocculation process for each of first and second treatments of proposed approach was 10 minutes, i.e., the sum of both times of flocculation process of proposed approach equal to that of conventional process (20 minutes). This mixing time of flocculation process is in agreement with that reported by [31] that recommended to consider the minimum mixing time for flocculation process ranges between 5 to 20 minutes for direct filtration and up to 30 minutes for conventional filtration.

Tables 2-4 show that the comparison of performance between conventional and proposed approaches on the basis of residual turbidity of each synthetic water using natural coagulants of (DS) and (PS) at their predetermined optimum doses as coagulant aids in conventional approach and as a primary coagulants in proposed approach under different investigated doses of alum $(A)$ as a primary coagulant in both approaches and various settling times from 30 to 120 minutes.

Table 2. The comparison of performance between conventional and proposed approaches to treat synthetic water at low turbidity.

\begin{tabular}{|c|c|c|c|c|c|c|c|c|c|c|}
\hline \multirow{3}{*}{$\begin{array}{l}\text { Natural } \\
\text { coagulant }\end{array}$} & \multirow{3}{*}{$\begin{array}{l}\text { Optimum } \\
\text { dose }(\mathrm{mg} / \mathrm{L})\end{array}$} & \multirow{3}{*}{$\begin{array}{l}\text { Alum dose } \\
\text { (mg/L) }\end{array}$} & \multicolumn{8}{|c|}{ Residual turbidity (NTU) } \\
\hline & & & \multicolumn{4}{|c|}{$\begin{array}{l}\text { Conventional approach } \\
\text { Settling time (min) }\end{array}$} & \multicolumn{4}{|c|}{$\begin{array}{l}\text { Proposed approach } \\
\text { Settling time (min) }\end{array}$} \\
\hline & & & 30 & 60 & 90 & 120 & 30 & 60 & 90 & 120 \\
\hline \multirow{5}{*}{ DS } & \multirow{5}{*}{30} & 2 & 46.4 & 34.5 & 22.5 & 19.6 & 25 & 20.53 & 16.58 & 14.37 \\
\hline & & 4 & 43.74 & 33.63 & 21.7 & 19.3 & 24.87 & 20.68 & 16.6 & 14.8 \\
\hline & & 6 & 42 & 32.64 & 23 & 20.4 & 24 & 19.89 & 16.2 & 13.7 \\
\hline & & 8 & 40.61 & 31.66 & 21.8 & 19.1 & 22 & 18.2 & 15.63 & 12.9 \\
\hline & & 10 & 40.07 & 31.1 & 20.7 & 18.1 & 2.69 & 0.49 & 0.2 & $\prec 0.1$ \\
\hline \multirow{5}{*}{ PS } & \multirow{5}{*}{20} & 2 & 55.2 & 35.2 & 30.1 & 25.06 & 33 & 28 & 23 & 19 \\
\hline & & 4 & 50.09 & 31.2 & 25.6 & 21.1 & 27 & 23 & 18 & 16 \\
\hline & & 6 & 38 & 20.1 & 16.04 & 13.08 & 23.6 & 18.3 & 15.1 & 14.1 \\
\hline & & 8 & 29.5 & 10.01 & 8.38 & 7.83 & 4.39 & 1.05 & 0.59 & 0.40 \\
\hline & & 10 & 15.7 & 4.67 & 3.25 & 2.17 & 3.62 & 0.42 & 0.30 & $\prec 0.1$ \\
\hline
\end{tabular}


Table 3. The comparison of performance between conventional and proposed approaches to treat synthetic water at medium turbidity.

\begin{tabular}{|c|c|c|c|c|c|c|c|c|c|c|}
\hline \multirow{3}{*}{$\begin{array}{l}\text { Natural } \\
\text { coagulant }\end{array}$} & \multirow{3}{*}{$\begin{array}{l}\text { Optimum } \\
\text { dose }(m g / L)\end{array}$} & \multirow{3}{*}{$\begin{array}{l}\text { Alum dose } \\
\text { (mg/L) }\end{array}$} & \multicolumn{8}{|c|}{ Residual turbidity (NTU) } \\
\hline & & & \multicolumn{4}{|c|}{$\begin{array}{l}\text { Conventional approach } \\
\text { Settling time (min) }\end{array}$} & \multicolumn{4}{|c|}{$\begin{array}{l}\text { Proposed approach } \\
\text { Settling time (min) }\end{array}$} \\
\hline & & & 30 & 60 & 90 & 120 & 30 & 60 & 90 & 120 \\
\hline \multirow{5}{*}{ DS } & \multirow{5}{*}{60} & 2 & 98.9 & 70.8 & 48.2 & 44.5 & 51.2 & 39.7 & 34 & 30.4 \\
\hline & & 4 & 94.2 & 62.9 & 45.3 & 42.9 & 48.4 & 37.1 & 31.8 & 29.3 \\
\hline & & 6 & 90.8 & 53.7 & 41.09 & 39.6 & 45.4 & 36.1 & 31.4 & 28.9 \\
\hline & & 8 & 86.9 & 48.1 & 37.9 & 33.4 & 11.6 & 5.3 & 5.13 & 4.67 \\
\hline & & 10 & 83.6 & 42.4 & 34.5 & 30.2 & 6.42 & 0.77 & 0.59 & $\prec 0.1$ \\
\hline \multirow{5}{*}{ PS } & \multirow{5}{*}{50} & 2 & 72.1 & 45.6 & 35.5 & 32.2 & 47.1 & 33.1 & 29.2 & 31.5 \\
\hline & & 4 & 60.02 & 40.7 & 30.6 & 27.2 & 39.2 & 29.04 & 25.03 & 28.02 \\
\hline & & 6 & 50.8 & 29 & 24.8 & 20.06 & 30.1 & 22.06 & 18.7 & 18.7 \\
\hline & & 8 & 39.9 & 19.6 & 16.5 & 14.5 & 6.25 & 2.10 & 0.76 & 0.54 \\
\hline & & 10 & 22 & 3.3 & 3.54 & 2.71 & 5.41 & 0.84 & 0.12 & 0.14 \\
\hline
\end{tabular}

Table 4. The comparison of performance between conventional and proposed approaches to treat synthetic water at high turbidity.

\begin{tabular}{|c|c|c|c|c|c|c|c|c|c|c|}
\hline \multirow{3}{*}{$\begin{array}{c}\text { Natural } \\
\text { coagulant }\end{array}$} & \multirow{3}{*}{$\begin{array}{l}\text { Optimum } \\
\text { dose (mg/L) }\end{array}$} & \multirow{3}{*}{$\begin{array}{l}\text { Alum dose } \\
\text { (mg/L) }\end{array}$} & \multicolumn{8}{|c|}{ Residual turbidity (NTU) } \\
\hline & & & \multicolumn{4}{|c|}{$\begin{array}{l}\text { Conventional approach } \\
\text { Settling time (min) }\end{array}$} & \multicolumn{4}{|c|}{$\begin{array}{l}\text { Proposed approach } \\
\text { Settling time (min) }\end{array}$} \\
\hline & & & 30 & 60 & 90 & 120 & 30 & 60 & 90 & 120 \\
\hline \multirow{5}{*}{ DS } & \multirow{5}{*}{80} & 2 & 95.03 & 58.1 & 45.06 & 41.08 & 22 & 9 & 8 & 7.5 \\
\hline & & 4 & 89.1 & 45.06 & 38.3 & 34.2 & 18.5 & 7.31 & 6.87 & 6.15 \\
\hline & & 6 & 69.2 & 30.9 & 26.7 & 24.2 & 12.4 & 1.16 & 0.48 & 0.25 \\
\hline & & 8 & 40.3 & 8.2 & 4.2 & 2.08 & 10.7 & 0.82 & 0.22 & $\prec 0.1$ \\
\hline & & 10 & 32.4 & 1.12 & 0.36 & $\prec 0.1$ & 10.4 & 2.03 & 1.88 & 1.55 \\
\hline \multirow{5}{*}{ PS } & \multirow{5}{*}{90} & 2 & 58.2 & 18.4 & 16.04 & 14.06 & 17.1 & 10.25 & 9.05 & 7.2 \\
\hline & & 4 & 52.1 & 14.6 & 11.3 & 10.08 & 9.65 & 3.37 & 3.16 & 3.43 \\
\hline & & 6 & 46.2 & 9.68 & 8.70 & 8.10 & 7.57 & 0.77 & 0.10 & 0.46 \\
\hline & & 8 & 28.5 & 0.22 & 0.14 & 0.09 & 6 & 1.01 & 0.52 & 0.75 \\
\hline & & 10 & 27.2 & 0.29 & 0.15 & 0.10 & 5.87 & 0.99 & 0.82 & 1.02 \\
\hline
\end{tabular}

In Table 2, at low turbidity, the conventional approach by using (DS) natural coagulant could not achieve the acceptable residual turbidity level in drinking water according to WHO. While for proposed approach, it could satisfy the acceptable limit (less of 5 NTU) at alum dose $(10 \mathrm{mg} / \mathrm{L})$ for all settling times from 30 to 120 minutes. It is of importance to mention that after 30 minutes settling time only, the residual turbidity was to be 2.69 NTU. This is very important not only for process economy but in the practical application. On the other hand, as the settling time increased, the residual turbidity decreased. The lowest value occurred at 120 minutes was less of 0.1 NTU. Note that, turbidmeter used in this work could not measure the turbidity values less of 0.1 NTU.

The same table shows the conventional approach by using (PS) natural coagulant produces appreciable reduction of turbidity that meeting the standard limit only at alum dose $(10 \mathrm{mg} / \mathrm{L})$ for settling times $(60,90,120 \mathrm{~min}-$ 
utes). While for proposed approach, it could satisfy the treatment goal ( $\prec 5 \mathrm{NTU})$ for all settling times from 30 to 120 minutes at two alum doses of 8 and $10 \mathrm{mg} / \mathrm{L}$. The advantage of proposed approach is to decrease settling time to 30 minutes that was capable of producing residual turbidities of 4.39 and 3.62 NTU for two alum doses 8 and $10 \mathrm{mg} / \mathrm{L}$ respectively. In addition, the use of 8 $\mathrm{mg} / \mathrm{L}$ alum will save $20 \%$ of process economy.

In Table 3, at medium turbidity, poor performance was observed when the use of (DS) as natural coagulant aid in conventional approach and consequently residual turbidities were higher than that of the acceptable limit of drinking water. Whilst, proposed approach using DS as a primary natural coagulant significantly reduced the residual turbidity to less than 5 NTU for settling times from 60 to 120 minutes at alum dose of $20 \mathrm{mg} / \mathrm{L}$ and 16 $\mathrm{mg} / \mathrm{L}$ for 120 minutes. In other words, the use of 16 $\mathrm{mg} / \mathrm{L}$ alum in proposed approach will save $20 \%$ of process economy.

The same table shows that at alum dose of $20 \mathrm{mg} / \mathrm{L}$, both approaches using (PS) natural coagulant achieved the treatment goal that less of 5 NTU for settling times from 60 to 120 minutes. In other words, the efficiency of proposed approach in terms of decreasing residual turbidity was better than of conventional approach. In addition, other alum dose $(16 \mathrm{mg} / \mathrm{L})$ in proposed approach showed excellent residual turbidity to meet WHO drinking water guidelines. The saving in alum dose at $16 \mathrm{mg} / \mathrm{L}$ using proposed approach was $20 \%$.

In Table 4, at high turbidity level, the conventional approach using (DS) natural coagulant achieved the acceptable limit in drinking water according to WHO for settling times $60,90,120$ minutes at alum dose of 60 $\mathrm{mg} / \mathrm{L}$ as well as $48 \mathrm{mg} / \mathrm{L}$ for settling times of 90 and 120 minutes. It is clear to see that the natural coagulant of (DS) showed a good coagulating activity in conjunction with alum at high turbidity of synthetic water. There is a range of optimum dosages for a coagulant at the best operating conditions to achieve efficiently and effectively the best results [35]. Proposed approach showed excellent residual turbidities that meeting WHO drinking water guidelines of three doses $(36,48,60 \mathrm{mg} / \mathrm{L})$ of alum for settling times of 60,90 and 120 minutes. The best performance of proposed approach in terms of residual turbidity occurred at alum dose of $48 \mathrm{mg} / \mathrm{L}$ compared with alum dose of $60 \mathrm{mg} / \mathrm{L}$ which representing the overdosing range of treatment. It is clear to notice that other residual turbidities of proposed approach at doses of 12 and $24 \mathrm{mg} / \mathrm{L}$ were close to meet standard level of drinking water compared with that of conventional approach. In general, the savings in alum dose for reducing costs of treatment was $20 \%$ for $48 \mathrm{mg} / \mathrm{L}$ and $40 \%$ for $36 \mathrm{mg} / \mathrm{L}$.

The same table shows conventional approach using (PS) natural coagulant achieved the required limit of treatment for both 48 and $60 \mathrm{mg} / \mathrm{L}$ at 60, 90, 120 minutes. While for proposed approach, dramatically minimizing and excellent performance in turbidity removal was observed at four doses of alum $(24,36,48,60 \mathrm{mg} / \mathrm{L})$ for three settling times from 60 to 120 minutes. Other residual turbidity (7.2) of proposed approach at alum dose of $12 \mathrm{mg} / \mathrm{L}$ was close to meet standard level of drinking water compared with that of conventional approach. The best investigated dose of alum in proposed approach was to be $36 \mathrm{mg} / \mathrm{L}$ that gave excellent removal efficiency in terms of minimum residual turbidity compared with other alum doses. Proposed approach significantly reduced alum dose $(60 \mathrm{mg} / \mathrm{L})$ to $20 \%$ at dose of $48 \mathrm{mg} / \mathrm{L}$ and $60 \%$ at dose of $24 \mathrm{mg} / \mathrm{L}$, thereby reducing costs of treatment. When using natural coagulants, considerable savings in chemicals and sludge handling cost may be achieved. Alum requirements could be saved by $50 \%$ $90 \%$ when okra was used as a primary coagulant or coagulant aid [36]. Natural coagulant such as moringa oleifera could produce readily biodegradable and less voluminous sludge by $20 \%-30 \%$ that of alum treated counterpart [37,38].

\section{Conclusions}

It has been found that in low and medium synthetic turbid water, conventional approach using (DS) natural coagulant could not achieve the acceptable residual turbidity level ( $\prec 5 \mathrm{NTU}$ ) in drinking water according to WHO. While (PS) natural coagulant produced appreciable reduction in turbidity that meeting WHO guidelines. Both of them showed a good coagulating activity in conjuncttion with alum at high synthetic water and produced residual turbidities less than 5 NTU.

The experimental results confirmed the efficiency of proposed approach was better than of conventional approach in terms of residual turbidity that meeting WHO drinking water guidelines using both (DS) and (PS) in conjunction with alum for low, medium and high bentonite synthetic water. It offers several significant economics and operational benefits such as it minimized alum dose required to $60 \%$, reduced settling time to 30 minutes and substantially decreased residual turbidities to less of 0.1 NTU. These advantages are very important not only for process economy through reducing the cost of treatments but in the practical application. Therefore, it is reasonable to consider this proposed approach to be a novel approach that applied as adequate pretreatment in advanced water treatment.

\section{Acknowledgements}

The author would like to grateful to Dr. Abdul Hameed M. Jawad Alobaidy, the director of Environmental Research Center-University of Technology/Iraq for his sup- 
port to achieve this research.

\section{REFERENCES}

[1] EPA, "Turbidity through the Treatment Processes," Guidance Manual Turbidity Provisions, 1999.

[2] AWWA and ASCE, "Water Treatment Plant Design," 2nd Edition, ASCE and AWWA, McGraw-Hill, Inc., New York, 1990.

[3] A. M. Warhurst, G. L. McConnachie and S. J. T. Pollard, "The Production of Activated Carbon for Water Treatment in Malawi from the Waste Seed Husks of Moringa Oleifera," Water Science and Technology, Vol. 34, No. 11, 1996, pp. 177-184. doi:10.1016/S0273-1223(96)00836-0

[4] S. Katayon, M. Noor, M. Asma, L. A. A. Ghani, A. M. Thamer, I. A. Azni, B. C. Khor and A. M. Suleyman, "Effects of Storage Conditions of Moringa Oleifera Seeds on Its Performance in Coagulation," Bioresource Technology, Vol. 97, No. 13, 2006, pp. 1455-1460. doi:10.1016/j.biortech.2005.07.031

[5] J. M. Montgomery, "Water Treatment-Principles and Design," Wiley Inter-Science, 1985.

[6] T. Okuda, A. U. Baes, W. Nishijima and M. Okada, "Improvement of Extraction Method of Coagulation Active Components from Moringa Oleifera Seed," Water Research, Vol. 33, No. 15, 1999, pp. 3373-3378. doi:10.1016/S0043-1354(99)00046-9

[7] V. J. H. Rondeau and D. D. J. F. Commenges, "Aluminum in Drinking Water and Cognitive Decline in Elderly Subjects," The Paquid Cohort American Journal of Epidemiology, Vol. 154, No. 3, 2001, pp. 288-290. doi:10.1093/aje/154.3.288-a

[8] E. Gauthier, I. Fortier, F. Courchesne, P. Pepin, J. Mortimer and D. Gauvreau, "Forms in Drinking Water and Risk of Alzheimer's Disease," Environmental Research, Vol. 84, No. 3, 2000, pp. 234-246. doi:10.1006/enrs.2000.4101

[9] B. Bolto and J. Gregory, "Organic Polyelectrolytes in Water Treatment," Water Research, Vol. 41, No. 11, 2007, pp. 2301-2324. doi:10.1016/j.watres.2007.03.012

[10] R. G. Miller, F. C. Kopfter, K. C. Kelty, J. A. Strober and N. S. Ulmer, "The Occurrence of Aluminum in Drinking Water," Journal of the American Water Works Association, Vol. 76, 1984, pp. 84-91.

[11] K .S. Narasiah, A. Vogel and N. N. Kramadhati, "Coagulation of Turbid Waters Using Moringa Oleifera Seeds from Two Distinct Sources," Water Science and Technology: Water Supply, Vol. 2, 2002, pp. 83-88.

[12] P. K. Raghuwanshi, M. Mandloi, A. J. Sharma, H. S. Malviya and S. Chaudhari, "Improving Filtrate Quality Using Agrobased Materials as Coagulant Aids," Water Quality Research, Vol. 37, No. 4, 2002, pp. 745-756.

[13] A. Diaz, N. Rincon, A. Escorihuela, N. Fernandez, E. Chacin and C. F. Forster, "A Preliminary Evaluation of Turbidity Removal by Natural Coagulants Indigenous to Venezuela," Process Biochemistry, Vol. 35, No. 3-4, 1999, pp. 391-395. doi:10.1016/S0032-9592(99)00085-0
[14] R. Sanghi, B. Bhatttacharya and V. Singh, "Cassia Angustifolia Seed Gum as an Effective Natural Coagulant for Decolourisation of Dye Solutions," Green Chemistry, Vol. 4, No. 3, 2002, pp. 252-254. doi:10.1039/b200067a

[15] M. Šciban, M. Klašnja and J. Stojimirovic, "Investigation of Coagulation Activity of Natural Coagulants from Seeds of Different Leguminose Species," Acta Periodica Technologica, Vol. 36, 2005, pp. 81-87. doi:10.2298/APT0536081S

[16] M. Šciban, M. Klašnja, M. Antov and B. Škrbic, "Removal of Water Turbidity by Natural Coagulants Obtained from Chestnut and Acorn," Bioresource Technology, Vol. 100, No. 24, 2009, pp. 6639-6643. doi:10.1016/j.biortech.2009.06.047

[17] V. Patale and P. Parikh, "A Preliminary Study on Coccinia Indica Fruit Mucilage Extract as Coagulant-Flocculent for Turbid Water Treatment," Journal of Pure and Applied Sciences, Vol. 18, 2010, pp. 27-30.

[18] N. A. Eman, A. M. Suleyman, M. S. Hamzah, Md. A. Zahangir and M. R. M. Salleh, "Production of Natural Coagulant from Moringa Oleifera Seed for Application in Treatment of Low Turbidity Water," Journal of Water Resource and Protection, Vol. 2, No. 3, 2010, pp. 259266. doi:10.4236/jwarp.2010.23030

[19] N. A. Eman, A. M. Suleyman, M. S. Hamzah, Md. A. Zahangir and M. R. M. Salleh, "Production of Natural Coagulant from Moringa Oleifera Seed for Drinking Water Treatment," South East Asia, Book 4, International Water Association (IWA) Publication, London, 2010.

[20] APHA (American Public Health Association), "Standard Methods for the Examination of Water and Wastewater," 20th Edition, APHA, AWWA, WEF, Washington DC, 1998.

[21] AWWA, "Operational Control of Coagulation and Filtration Processes," 2nd Edition, American Water Works Association, Denver, 2000.

[22] A. Mishra, R. Srinivasan, M. Bajpai and R. Dubey, "Use of Polyacrylamide-Grafted Plantago Psyllium Mucilage as a Flocculant for Treatment of Textile Wastewater," Colloid and Polymer Science, Vol. 282, No. 7, 2004, pp. 722-727. doi:10.1007/s00396-003-1003-1

[23] A. Mishra and M. Bajpai, "Flocculation Behaviour of Model Textile Wastewater Treated with a Food Grade Polysaccharide," Journal of Hazardous Materials, Vol. 14, No. 118, 2005, pp. 213-217. doi:10.1016/j.jhazmat.2004.11.003

[24] M. Chaudhuri and P. S. A. B. Khairuldin, "Coagulation-Clarification of Coloured Water by Natural Coagulant (Moringa oleifera) Seed Extract," Nature Environment and Pollution Technology, Vol. 8, No. 1, 2009, pp. 137-139.

[25] V. N. R. Divakaran and P. Sivasankara, "Flocculation of River Silt Using Chitosan," Water Research, Vol. 36, No. 9, 2002, pp. 2414-2418. doi:10.1016/S0043-1354(01)00436-5

[26] A. Diaz, N. Rincon, A. Escorihuela, N. Fernandez and C. F. Forster, "A Preliminary Evaluation of Turbidity Removal by Natural Coagulants Indigenous to Venezuela," 
Process Biochemistry, Vol. 35, No. 3, 1999, pp. 391-395. doi:10.1016/S0032-9592(99)00085-0

[27] T. Nkurunziza, J. B. Nduwayezu, E. N. Banadda and I. Nhapi, "The Effect of Turbidity Levels and Moringa Oleifera Concentration on the Effectiveness of Coagulation in Water Treatment," Water Science and Technology, Vol. 59, No. 8, 2009, pp. 1551-1558. doi: $10.2166 /$ wst.2009.155

[28] A. Konstantinos, K. Dimitrios and D. Evan, "Flocculation Behavior of Mallow and Okra Mucilage Intreating Wastewater," Desalination, Vol. 249, No. 2, 2009, pp. 786-791. doi:10.1016/j.desal.2008.09.013

[29] T. Okuda, A. U. Baes, W. Nishijima and M. Okada, "Coagulation Mechanism of Salt Solution-Extracted Active Component in Moringa Oleifera Seeds," Water Research, Vol. 35, No. 3, 2001, pp. 830-834. doi:10.1016/S0043-1354(00)00296-7

[30] WHO, "Water Quality Monitoring - A practical Guide to the Design and Implementation of Freshwater Quality Studies and Monitoring Programs," United Nations Environment Program and the World Health Organization, Geneva, 1996.

[31] EPA, "Water Treatment Manual," Coagulation, Flocculation \& Clarification, 2002.

[32] L. K. Wang, Y.-T. Hung and N. K. Shammas, "Physicochemical Treatment Processes," Handbook of Environ- mental Engineering, The Humana Press Inc., Totowa, Vol. 3, 2005.

[33] B. Bina, "The Use of Moringa Oleifera Seed as Natural Plant Coagulant in Removal of Clay Particles and E. coli," Water \& Sewage, Vol. 14, 1995, pp. 4-12.

[34] B. Bina, M. H. Mehdinejad, M. Nikaeen and H. A. Movahedian, "Effectiveness of Chitosan as Natural Coagulant Aid in Treating Turbid Waters," Iranian Journal of Environmental Health Science \& Engineering, Vol. 6, No. 4, 2009, pp. 247-252.

[35] W. Culp, "Handbook of Public Water Systems," Van Nostrand Reinhold Company, New York, 1986.

[36] A. A. Al-Samawi and E. M. Shokrala, "An Investigation into an Indigenous Natural Coagulant," Journal of Environmental Science and Health, Vol. 31, No. 8, 1996, pp. 1881-1897. doi:10.1080/10934529609376463

[37] A. Ndabigengesere, K. S. Narasiah and B. G. Talbot, "Active Agents and Mechanisms of Coagulation of Turbid Water Using Moringa Oleifera," Water Research, Vol. 29, No. 2, 1995, pp. 703-710. doi:10.1016/0043-1354(94)00161-Y

[38] K. S. Narasiah, A. Vogel and N. N. Kramadhati, "Coagulation of Turbid Waters Using Moringa Oleifera Seeds from Two Distinct Sources," Water Science and Technology: Water Supply, Vol. 2, No. 5-6, 2002, pp. 83-88. 